Article

\title{
Evaluation of Cyanea capillata Sting Management Protocols Using Ex Vivo and In Vitro Envenomation Models
}

\author{
Thomas K. Doyle 1,* (D), Jasmine L. Headlam ${ }^{1}$, Christie L. Wilcox ${ }^{2}$ (D), Eoin MacLoughlin ${ }^{1}$ \\ and Angel A. Yanagihara $2,3, *$ (iD \\ 1 Discipline of Zoology, School of Natural Sciences, Ryan Institute, National University of Ireland Galway, \\ Galway H91 W5P7, Ireland; J.HEADLAM1@nuigalway.ie (J.L.H.); eoin.macloughlin@nuigalway.ie (E.M.) \\ 2 Department of Tropical Medicine, Medical Microbiology and Pharmacology, John A. Burns School of \\ Medicine, University of Hawaii at Mānoa, Honolulu, HI 96813, USA; wilcoxcl@hawaii.edu \\ 3 Békésy Laboratory of Neurobiology, Pacific Biosciences Research Center, School of Ocean and Earth Science \\ and Technology, University of Hawaii at Mānoa, Honolulu, HI 96822, USA \\ * Correspondence: tom.doyle@nuigalway.ie (T.K.D.); ayanagih@hawaii.edu (A.A.Y.); \\ Tel.: +353-091-493744 (T.K.D.); +1-808-956-8328 (A.A.Y.)
}

Academic Editor: Bryan Grieg Fry

Received: 2 June 2017; Accepted: 3 July 2017; Published: 7 July 2017

\begin{abstract}
Lion's mane jellyfish (Cyanea capillata) stings cause severe pain and can lead to dangerous systemic effects, including Irukandji-like syndrome. As is the case for most cnidarian stings, recommended medical protocols in response to such stings lack rigorous scientific support. In this study, we sought to evaluate potential first aid care protocols using previously described envenomation models that allow for direct measurements of venom activity. We found that seawater rinsing, the most commonly recommended method of tentacle removal for this species, induced significant increases in venom delivery, while rinsing with vinegar or Sting No More ${ }^{\circledR}$ Spray did not. Post-sting temperature treatments affected sting severity, with $40 \mathrm{~min}$ of hot-pack treatment reducing lysis of sheep's blood (in agar plates), a direct representation of venom load, by over $90 \%$. Ice pack treatment had no effect on sting severity. These results indicate that sting management protocols for Cyanea need to be revised immediately to discontinue rinsing with seawater and include the use of heat treatment.
\end{abstract}

Keywords: Scyphozoa; cnidarian envenomations; first aid; hair jelly

\section{Introduction}

Jellyfish of the genus Cyanea are widely distributed in temperate, boreal and polar waters of the Pacific and Atlantic Oceans [1-5]. While all Cyanea species are known to be venomous, the lion's mane jellyfish (Cyanea capillata) has been medically problematic for at least 100 years [6]. It is a large jellyfish (up to $1 \mathrm{~m}$ bell dimeter) with eight groups of $~ 100$ tentacles each located on the subumbrellar side of the jellyfish [7]. In Irish and UK waters, lion's mane jellyfish can be encountered from June until late September [4]. It is one of the least abundant jellyfish in Irish and UK waters, typically occurring as single individuals rather than in blooms or aggregations [4,8]. Despite being one of the least abundant jellyfish, relatively high densities of lion's mane jellyfish have been recorded close to high population centers (e.g., Dublin Bay), making stings a frequent problem. Furthermore, open-ocean swimming is very popular in the UK and Ireland, and many swimming clubs and events are held in areas where lion's mane jellyfish are known to be abundant, and therefore stings are a recurrent concern. Over the past 10 years, there have been several beach closures due to the lion's mane jellyfish and at other times signs have been put in place warning bathers that the water is not safe to swim because of 
the lion's mane jellyfish. Indeed, during a previous study in this area, $51 \%$ of bathers $(n=77)$ said that they had been badly stung by a jellyfish, and three said they required treatment at a hospital (T.K.D., unpublished data). While no central database exists in Ireland documenting the numbers of sting incidents requiring medical attention, it is likely between 10 and 100 persons per year (T.K.D., pers. obs.).

Cyanea stings, though not generally considered fatal, can cause severe local reactions, including extreme pain and edema, as well as systemic symptoms and clinical signs [9-14]. Envenomations involving large specimens can be particularly dangerous, as the thousands of almost invisibly thin tentacles can each extend to several meters long. Initial dermal contact may result in itching or localized pain that may radiate to other areas of the body, potentially progressing to severe pain within $20 \mathrm{~min}$ or more. Weakness, vertigo, nausea, headache, muscle cramps, lacrimation and perspiration may also occur. In very severe stings, there may be difficulty breathing and pain on respiration, tachycardia, muscle spasms and stiffness of back and joints. The skin may become red with urticarial weals, local edema, blisters and weeping of the skin, which may progress to ulceration and secondary infection. In some cases, stings can result in Irukandji-like syndrome (i.e., symptoms include back "pain, nausea, abdominal cramps, sweating, hypertension, tachycardia and a feeling of impending doom" and usually develop 20-60 min after a sting [15]).

Currently, sting management protocols suffer from a lack of rigorous evidence-based support. For example, a recent literature review [16] found very few studies evaluating recommended sting protocols for species found in German waters (including C. capillata), and those that were identified were classified level 4 or less on the evidence classification scale, as described by the Oxford Centre for Evidence-Based Medicine (CEBM) [17]. Previous reviews have similarly found scant evidence supporting first aid methods for C. capillata stings $[18,19]$. For C. capillata specifically, only two studies have been conducted which evaluate the efficacy of potential first aids $[20,21]$. The only study examining potential removal methods was conducted more than 30 years ago, relied solely on in vitro examination of nematocyst discharge in response to potential rinse solutions, and did not include quantitative results, raw data images, or statistical comparisons between treatments [21]. Recent work has demonstrated that nematocyst discharge in vitro has limited (if any) correlation to sting severity as measured by direct functional assays [22] or human clinical trials [23]. Similarly, the only study supporting the use of cold packs for pain relief was uncontrolled and contained no statistical analysis [20].

Despite the dearth of studies evaluating the effects of potential interventions, most authorities currently recommend that $C$. capillata tentacles be removed by rinsing with seawater/saline $[13,18,24-26]$ (references stating that vinegar rinsing is specifically contraindicated $[9,18,24]$ ), and that the sting site should be treated with either hot water immersion/heat [24,25], cold packs/ice [18,26], or a baking soda slurry $[9,25,27,28]$. In the clinical literature, medical databases and lay-level advice articles, species-specific recommendations are often not given; instead, general recommendations are made for all 'jellyfish' (sometimes limited by geographic area) [26,29-31], all scyphozoan species (sometimes lumped as 'sea nettles') [27,32], or all non-tropical and/or non-cubozoan species [33-35]. For these reasons evidence based research utilizing direct activity assays are urgently needed to systematically evaluate medically relevant species.

The purpose of this study was to re-evaluate common first aid recommendations for C. capillata stings using a combination of in vitro discharge tests, as well as envenomation models which evaluate functional venom activity [36]. Potential rinse solutions (seawater, urine, vinegar, and Sting No More ${ }^{\circledR}$ Spray), as well as temperature treatments (hot packs versus ice packs) were evaluated. 


\section{Results}

\subsection{Testing of Potential Rinse Solutions Using the Tentacle Solution Assay}

To compare with previous investigations and studies conducted on other species, we examined the in vitro effects of potential rinse solutions using the Tentacle Solution Assay (TSA) [36]. However, precise quantification of nematocyst discharge in response to test solutions proved difficult given the complexity of the Cyanea cnidome, which consists of euryteles, birhopaloids and three different isorhizas-a-isorhizas, A-isorhizas, and O-isorhizas_each with multiple size classes [37] (Figure 1). It is essential to distinguish these types when evaluating discharge because studies have demonstrated that different nematocysts can vary not only in their morphology and penetrant abilities but also in their toxic effects [38-40]. However, precise quantification of percent discharge for each nematocyst type and size class was not possible with the microscope and camera available for this study; best efforts were made to identify cnidae types based on [37]. Further, it is also likely that some of the cnidae visualized in this study are immature, particularly smaller cnidae [37]; it was not possible to distinguish immature versus mature cnidae in this study.



Figure 1. Cyanea tentacles viewed microscopically. (A) Tentacle viewed at $10 \times$ magnification; discrete 'batteries' of cnidae can be seen, each containing a mix of different cnidae types. (B) $40 \times$ magnification of a typical tentacle battery showing the complex and difficult to identify cnidome; cnidae identified according to [37]. a, a-isorhizas; A, A-isorhiza; e, euryteles; Oi, O-isorhizas; bi, birhopaloids.

Seawater is an inert solution, and did not elicit discharge (Figure 2A). When tentacles were treated with vinegar (Figure 2B), some discharge of cnidae did occur, but discharge was not equally distributed between cnidae types. Cnidae identified as a-isorhizas and euryteles (or possibly immature cnidae, based on their size) discharged to some extent ( $<20 \%$ discharge; white arrows), but A-isorhizas, O-isorhizas and birhopaloids largely did not (estimated $<5 \%$ discharge of each). In contrast, the application of urine (Figure 2C) and isopropanol (Figure 2D) induced $~ 50 \%$ discharge in all cnidae 
types. Pressure also led to $\sim 50 \%$ discharge of all cnidae types (data not shown). Therefore, while these results are qualitative rather than quantitative, there were clear differences between the different treatments with no response from sea water, mostly $<5 \%$ firing of cnidae for vinegar (except for a-isorhizas and euryteles which had a $<20 \%$ firing rate) and then $\sim 50 \%$ firing rate for all other treatments: urine, isopropanol and pressure.

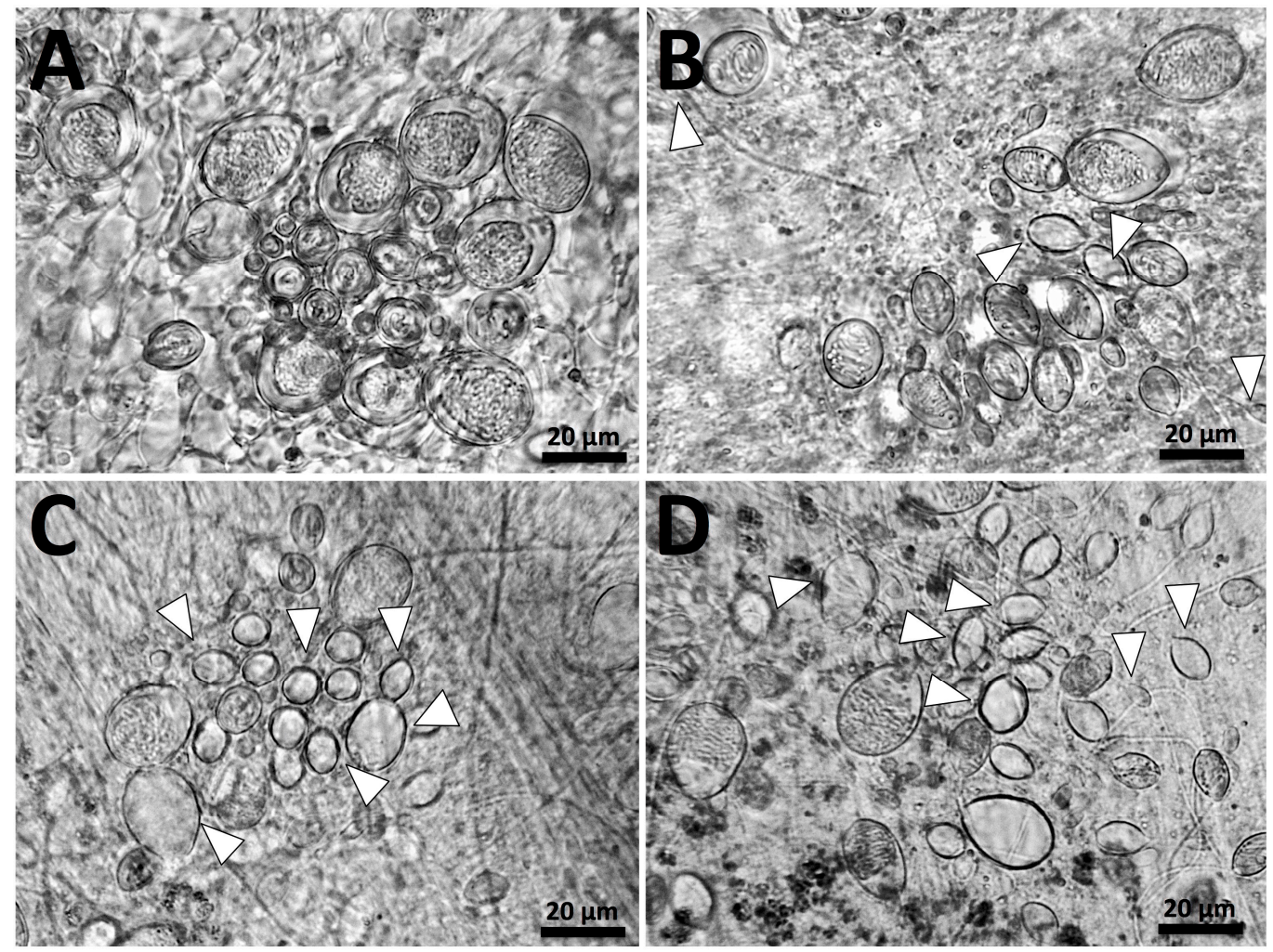

Figure 2. Cyanea cnidae discharge in response to (A) seawater; (B) vinegar; (C) urine; (D) isopropanol. No discharge can be seen in (A), while (B-D) all contain discharged cnidae (examples indicated with white arrows). However, the discharge in $(\mathbf{B})$ is only partial $(<20 \%)$ and limited to putative a-isorhizas and euryteles, while (C,D) show moderate discharge $(\sim 50 \%)$ of all cnidae types.

Since previous studies have found discrepancies between discharge seen in vitro and venom activity in functional assays [22], the effects of vinegar on cnidae discharge were further examined in a stinging model. Tentacles were placed upon 5\% gelatin and remained in place for 5 min. Tentacles were then pulled off with tweezers, and adherent cnidae were examined microscopically to discern cnidae type, relative abundances and proportional type-specific discharge. Among the adherent cnidae, smaller size classes were more likely to be discharged (Figure 3A, white arrows). While recording video (see Video S1), vinegar was added directly to the adherent cnidae to evaluate whether vinegar application induced any specific morphological response. This was done to address the question as to whether vinegar rinsing could result in functional discharge (i.e., envenomation) if used as a post-sting rinse (before vinegar, Figure 3A; after vinegar, Figure 3B). While many cnidae did not react to vinegar (e.g., Figure 3, black arrow), specific cnidae types evidenced morphological responses (Figure 3, grey arrows). It should be noted that while intact cnidae capsules respond to various stimuli, the response can include non-everting rupture, partial eversion discharge, and fully everting discharge in which the tubule productively impales the substrate (prey tissue) as well as eversions in which the tubule non-productively discharges into the surrounding seawater. For this reason it is noteworthy that among cnidae that discharged in response to vinegar application, all of the tubules appeared to evert non-productively upwards into the vinegar droplet and did not impale the gelatin (Figure 3B, 
grey arrows; Video S1). Thus, no envenomating discharge of cnidae was observed in response to vinegar application, suggesting that the subpopulation of cnidae that are triggered to discharge in response to the application of vinegar are either not penetrant venom-laden nematocysts, or that if they are nematocysts, this type of capsule rupture does not result in functional venom delivery. Instead, vinegar application may essentially inactivate this subpopulation of cnidae by inducing aberrant capsule rupture rather than authentic trauma inducing discharge.
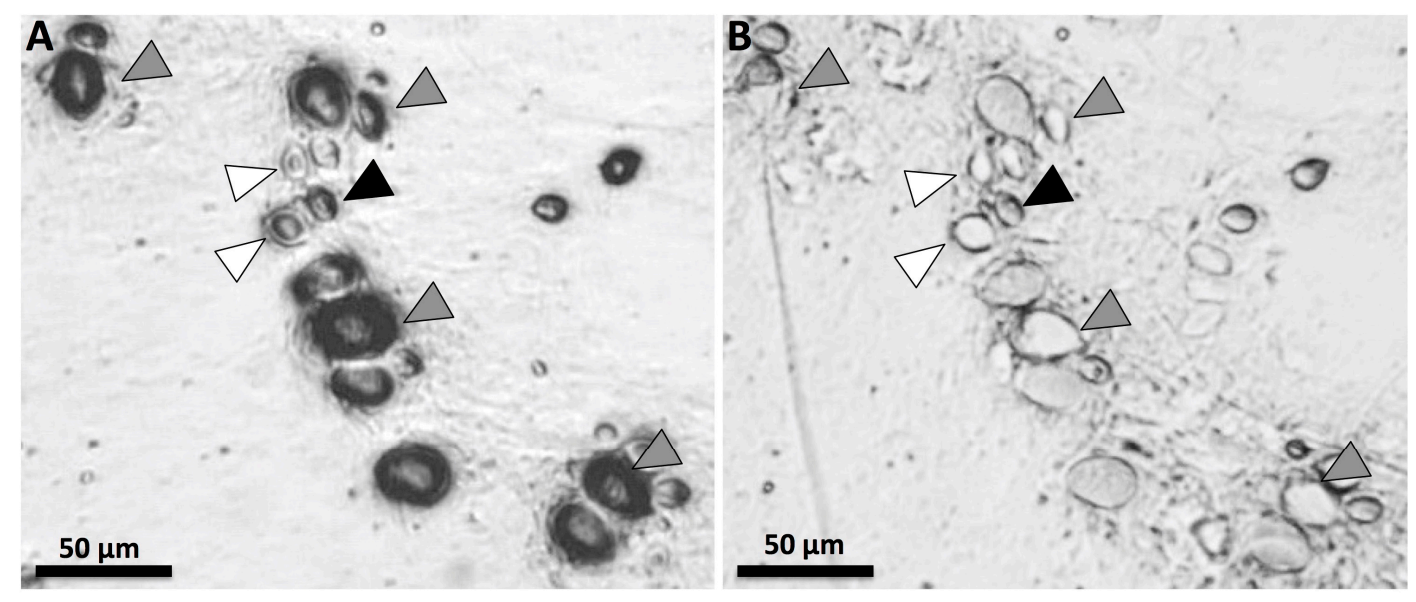

Figure 3. Nematocysts remaining on $5 \%$ gelatin after a $5 \mathrm{~min}$ C. capillata sting before (A) and after (B) vinegar application. White arrows indicate discharged, penetrant nematocyst and black arrows indicate non-discharged nematocysts that did not discharge at any point during the experiment. Grey arrows point to nematocysts that discharged in response to vinegar application; however, in all cases, tubules could be seen everting upwards into the vinegar droplet and not penetrating the gelatin below, suggesting that no additional venom delivery into the gelatin in response to vinegar application despite the solution causing nematocyst discharge.

\subsection{Testing of First Aid Measures Using Functional Models}

In addition to solution-based assays, functional venom activity assays were conducted using live, spontaneously stinging tentacles [36]. We sought to evaluate whether the rinse solutions tested in TSAs as well as post sting topical hot-, ambient- or cold-pack exposure (for which there is no method for testing using TSAs) led to increases or decreases in hemolytic zone formation, a function metric of venom activity or "venom load".

Different rinse solutions significantly affected the size of the hemolytic zone after $12 \mathrm{~h}$ (one-way ANOVA, $p<0.0001$; Figure 4 ). When compared with simply pulling off tentacles, the application of urine or seawater significantly increased hemolysis $(p=0.0350$ and 0.0001 , respectively in Fisher's LSD post-hoc analyses), while the use of vinegar or Sting No More ${ }^{\circledR}$ Spray reduced hemolysis $(p=0.0061$ and 0.0045 , respectively). These results conflict our TSA results, which found that seawater was "inert" (did not induce discharge) while vinegar did induce some cnidae discharge (Figure 2B, Figure 3), suggesting that the in vitro studies do not accurately predict actual venom delivery during stings. 




Figure 4. Size of venom-induced hemolytic zone after $12 \mathrm{~h}$ using the TSBAA model (sheep's blood agarose) when C. capillata tentacles were removed by rinsing with seawater (dark blue), urine (yellow), vinegar (orange) or Sting No More ${ }^{\circledR}$ Spray (green); $N=3$ for each, points represent mean \pm standard error. The addition of seawater or urine significantly increased the size of the hemolytic area $(p=0.0350$ and 0.0001 , respectively in Fisher's LSD post-hoc analyses), while the use of vinegar or Sting No More ${ }^{\circledR}$ Spray reduced hemolysis ( $p=0.0061$ and 0.0045 , respectively); asterisks denote level of significance from no first aid: one asterisk for $p<0.05$, two for $p<0.01$ and three for $p<0.001$.

The application of post-sting temperature treatments for $40 \mathrm{~min}$ also significantly affected sting severity (Figure 5). Over time, greater differences in hemolysis were seen between hot packs and ice packs (Figure 5B), resulting in significantly less hemolysis from stings treated with hot packs after $24 \mathrm{~h}$ (Figure 5A). All three treatments in hot/cold experiment 2 (Figure 5B) showed much greater hemolysis than the first experiment (Figure 5A). No differences were detected between stings that did not receive a temperature treatment and those that received ice. 

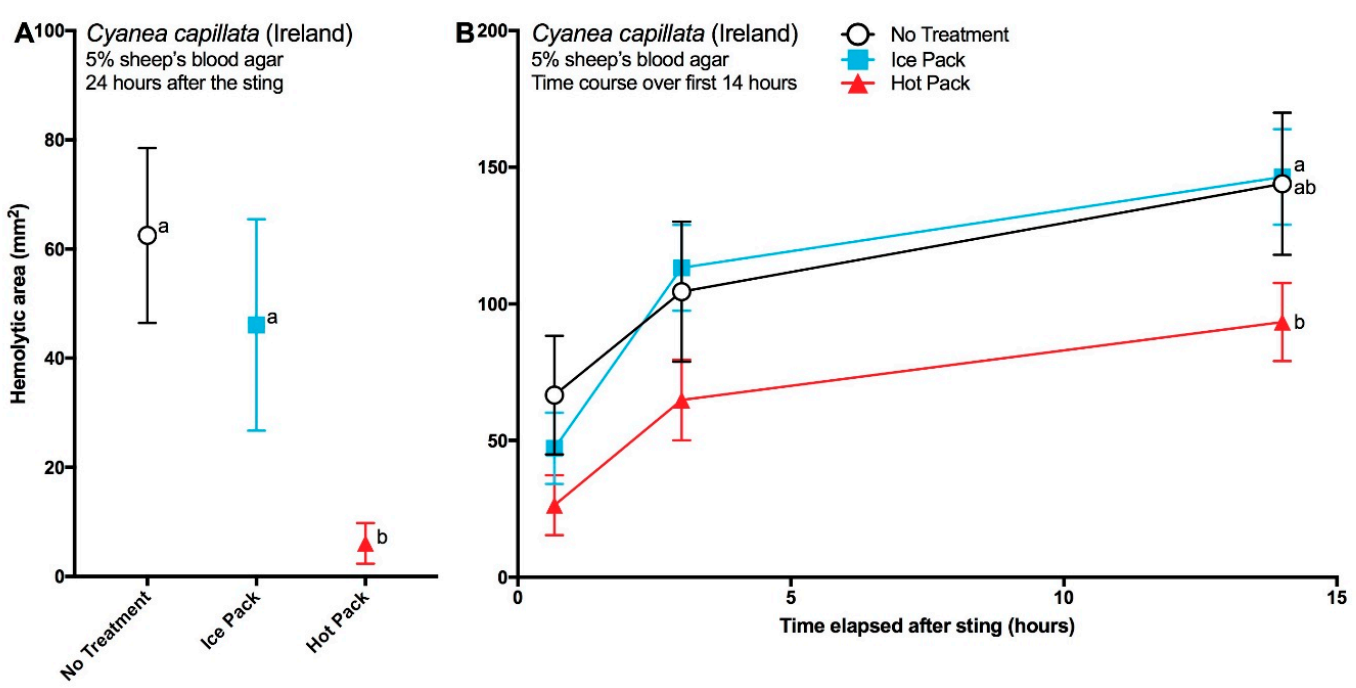

Figure 5. Size of venom-induced hemolytic zone from two experiments using the Tentacle Skin Blood Agarose Assay (TSBAA) model (sheep's blood agar) when stings were treated with hot packs (red triangles), ice packs (blue squares), or kept at room temperature (circles); $N=6$ for all, points represent mean \pm standard error. (A) Experiment 1 was carried out on the 27th July 2016 and the hemolytic zone was reported after $24 \mathrm{~h}$ and in (B) Experiment 2 was carried out on 4th August 2016 and the hemolytic zone was measured at three time periods ( $40 \mathrm{~min}, 3 \mathrm{~h}$ and $14 \mathrm{~h}$ ). In experiment 1 , there were significant differences between the treatments after $24 \mathrm{~h}$ (one-way ANOVA, $p<0.0001$ ), with hot packs significantly reducing the hemolytic area size when compared with either ice packs $(p<0.0001$, Fisher's LSD) or no temperature treatment $(p=0.0004)$. In experiment 2 , a significant difference was detected at the $14 \mathrm{~h}$ time period between hot and cold treatments ( $p=0.0483$, Two-Way ANOVA with post-hoc Fisher's LSD) using a two-way ANOVA.

\section{Discussion}

The current recommendations for treating Cyanea stings vary greatly depending on the source. Most recommend rinsing the sting site with seawater or saline $[13,18,24-26]$ followed by hot water immersion/heat [24,25], cold packs/ice [18,26], or a baking soda slurry $[9,25,27,28]$. We did not evaluate the last option in this study. However, we found that seawater rinsing increased functional venom delivery or "venom load" and that there was no benefit from the use of ice. Instead, our results support the use of vinegar to rinse away adherent tentacles and treatment with at least 40 min of $45^{\circ} \mathrm{C}$ heat to limit injected venom activity.

It may seem surprising that rinsing with vinegar led to significant decreases in venom activity (Figure 4) given that it induces some cnidae discharge in vitro (Figures 2 and 3). In our study, we noted that vinegar does not equally induce discharge in all nematocyst types, and did not elicit as much discharge as other solutions (urine, isopropanol). It is not known how each nematocyst type contributes to toxicity, but previous studies have suggested that the largest A-isorhizas and O-isorhizas disproportionately contribute to hemolysis [40], and these cnidae types were not triggered by vinegar application. Thus, it may be that vinegar does not induce discharge of the most toxic types of nematocysts, and that any discharge that occurs during the rinsing process does not contribute measurably to hemolytic activity, the functional metric of our venom activity assays. Or, as seen when vinegar was applied to adherent cnidae in our simple gelatin sting model (Figure 3), it is possible that vinegar application induces agonal, biologically inactive discharge (as suggested by Auerbach [41]), rendering cnidae incapable of functionally delivering venom. Upon tentacle contact with skin, a certain percentage of cnidae immediately discharge. However, a great number of cnidae were found to have been transferred to the skin intact. Because sea water does not irreversibly inhibit cnidae discharge, cnidae left at the contact site retain the capacity to discharge and thus as the tentacle rolls 
along the skin during the sea water rinse, additional undischarged cnidae are transferred beyond the original "sting" site. Finally, the data in this study demonstrate that these residual undischarged cnidae discharge spontaneously over the time course examined, to result in a greater area of a hemolytic zone as shown is Figure 4. Urine, a commonly believed folk remedy for jellyfish stings, was even worse than seawater (Figure 4), which aligns with out TSA data showing it elicits $\sim 50 \%$ discharge of all cnidae types. These results stress the importance of evaluating first aid protocols using functional activity assays rather than solution-only tests, as they add to a growing number of studies that have shown in vitro examinations are not necessarily predictive of clinically relevant effects $[22,23,42]$.

Overall the hot pack treatment reduced sting severity despite the observed variability in venom potency between the two experiments (Figure 5A,B). This may reflect individual animal variability in potency or differences in the duration of time between animal capture at sea and the removal of tentacles for the experiments. Nonetheless, the observed reduction of venom activity by heat (Figure 5) is in concurrence with similar studies in hydrozoans [42] and cubozoans [22,36] and the body of clinical literature that demonstrates improved clinical outcomes with heat application as well as the low level of heat thermotolerance of cnidarian venoms (for a review see [43]). Some have suggested that improved outcomes from heat application (in particular the reduction of pain seen in clinical studies [44-46]) are not the result of reduction in venom activity, but instead, reflect modulation of neurological pain processing [47]. This is directly disputed by the results of our envenomation modeling, where we demonstrate a direct dampening effect of heat application on venom activity in a model system that lacks any neurons or neural pathways. And as similar results have been achieved across three separate cnidarian classes, these data suggest that cnidarian venoms in general are heat-sensitive and that the sustained application of heat (at least $40 \mathrm{~min}$ ), in the form of $45^{\circ} \mathrm{C}$ hot packs or hot water immersion, is an effective first aid for reducing the damage caused by injected venom. Indeed recent research has shown that a crude venom extract from Pelagia noctiluca (another scyphozoan jellyfish) also exhibits a loss of potency at temperatures higher than $\left.40^{\circ} \mathrm{C}[48,49]\right)$. Similarly, biochemical studies have shown marked $45^{\circ} \mathrm{C}$ heat related loss of activity in vitro [50-64] which may reflect thermal unfolding or aggregation. Additional research is needed to determine exactly why heat has this direct, negative effect on venom activity; there may be less evolutionary pressure for heat tolerance among cnidarian venom proteins than mammalian proteins. Taken together, the observation that venom protein activities are significantly inhibited at tolerably hot temperatures far below those required to induce mammalian protein biophysical denaturation, (i.e., measurable loss of tertiary or secondary structure) provides the basis for safe first aid reduction of the activity of lytic components.

Because of the great diversity of stinging jellyfish (cubozoans, hydrozoans and scyphomedusae), it has been previously stated that different jellyfish may require different treatments $[9,65]$. Building on previous work on box jellyfish [22,43] and the Portuguese man o' war [42], this study now shows that jellyfish from three different classes of Cnidaria (Cubozoa, Hydrozoa and Scyphozoa) respond in the same way to the application of vinegar (despite slight differences in response to vinegar in vitro) and heat. This will therefore, simplify the development of a first aid protocol for jellyfish stings even in countries that have several very different venomous jellyfish species.

\section{Conclusions}

As C. capillata envenomations represent a significant medical burden worldwide, it is important that evidence-based medical treatments be employed when generating first aid management protocols. We found that despite inducing some detectable cnidae discharge in vitro, vinegar was the most effective non-commercial rinse solution for safely removing adherent tentacles and nematocysts. The commercial product Sting No More ${ }^{\circledR}$ Spray was equally effective, while the use of seawater and urine exacerbated stings. We also found the application of a $40-\mathrm{min}, 45^{\circ} \mathrm{C}$ hot pack reduced the activity of successfully injected venom, and thus worked well as a treatment. Because our model does not include metrics for pain or neurological processes, we are able to affirm that heat has a direct effect on venom proteins rather than an indirect, modulating effect on pain sensory systems. Heat application 
reduced the activity of injected venom, while the application of ice had no significant effect. Thus, we conclude that the best first aid for $C$. capillata stings is a two-step protocol of (1) rinsing with vinegar or Sting No More ${ }^{\circledR}$ Spray and (2) 40 min or longer treatment with hot packs or hot water immersion $\left(45^{\circ} \mathrm{C} / 113^{\circ} \mathrm{F}\right)$.

\section{Materials and Methods}

The chemicals for the solutions used in all assays are as follows: seawater (locally collected), freshwater (tap water), distilled white vinegar (Tesco, produced in the UK for Tesco Stores Ltd., Chestnut, UK for experiments conducted in Ireland; Market Pantry, Target Corporation, Minneapolis, MN, USA for those conducted in the USA), isopropanol (91\%, Up \& Up, Target Corporation, Minneapolis, MN, USA), Sting No More ${ }^{\circledR}$ Spray (contents include vinegar, copper gluconate, urea, and magnesium sulfate; Alatalab Solutions ${ }^{\text {TM }}$ LLC, Honolulu, HI, USA), and gelatin (Knox ${ }^{\circledR}$ Gelatine, Kraft Food Groups, Inc., Northfield, IL, USA). Urine was freshly collected from a willing volunteer (pH 5.25).

\subsection{Animal Collection}

For in vitro examination, tentacles were collected just prior to experiments from live C. capillata harvested from Puget Sound and kept in aquaria at the Point Defiance Zoo and Aquarium in Tacoma, WA. Animals had spent approximately one year in captivity prior to experiments. For functional assays involving blood cells, live C. capillata were collected from Dublin Bay (between the Forty Foot bathing area and Dalkey Island, $\left.53.288402^{\circ} \mathrm{N},-6.103343^{\circ} \mathrm{W}\right)$. Animals were placed in individual $50 \mathrm{~L}$ containers full to the brim with seawater to prevent damage to the animals from sloshing during transport. Tentacles were harvested just prior to their use in experiments; all experiments were conducted within $72 \mathrm{~h}$ of collection.

\subsection{Tentacle Solution Assay (TSA) and In Vitro Tests}

To test for the induction of discharge, freshly cut tentacles (length 1-2 cm) from a captive specimen of C. capillata housed at the Point Defiance Zoo and Aquarium were placed on clean, dry microscope slides and examined quickly for discharge; any lengths with notable discharge were discarded [36]. $60 \mu \mathrm{L}$ of the test solution was then added to the tentacle. Test solutions were (a) sea water, (b) vinegar, (c) urine and (d) isopropanol (Sting No More ${ }^{\circledR}$ Spray was not used during the test as it was not available). After one minute of incubation, a cover slip was gently placed over the tentacle. Preliminary tests with seawater confirmed that coverslip addition did not induce significant discharge. All photos were taken of the tentacles ten minutes after the various treatments through the coverslip using a compound microscope at $10 \times$ and $40 \times$ magnification (microscope: OMAX M837ZL Compound Microscope, OMAX, Bucheon, South Korea; camera: OMAX A35140U; photo software: ToupLIte vers. 1.0., ToupTek, Zhejiang, China).

To further evaluate discharge in response to vinegar, tentacles were allowed to sting a $2 \mathrm{~mm}$ thick slab of $5 \%$ gelatin in seawater for five minutes. After tentacles were pulled off using tweezers, adherent cnidae were examined microscopically at $10 \times$ magnification. A video was taken as vinegar was applied to an area with both discharged and undischarged cnidae, and one minute of footage was recorded. Video footage was examined to determine whether vinegar application induced any nematocysts in the field of vision to discharge and, if so, whether the everting tubules penetrated the gelatin substrate (microscope: AmScope M158C-E Compound Monocular Microscope, AmScope, Irvine, CA, USA; camera: AmScope MD35; photo software: Proscope HR version 1.2.1., Bodelin, Wilsonville, OR, USA).

\subsection{Evaluating First Aid Measures with Functional Assays (Tentacle Skin Blood Agarose Assay, or TSBAA)}

The effect of solutions and temperature treatments on sting severity was evaluated using a "skin" covered adaptation of the Tentacle Blood Agarose Assay (TBAA) ex vivo envenomation model outlined 
in [36]. Briefly, premade sheep's blood agar plates (Remel ${ }^{\mathrm{TM}}$, Lenexa, KS, USA) were used for the Tentacle Skin Blood Agarose Assay (TSBAA).

For rinse experiments, 15 blood agarose rounds were extracted from the blood agar plates $(20 \mathrm{~mm}$ diameter). These rounds were placed on top of a layer of cling film laid over the open end of a glass jar (diameter approx. $45 \mathrm{~mm}$ ). Sections of the prepared ovine intestine were laid over the agar rounds. The lids of the glass jars had a hole approx. $25 \mathrm{~mm}$ cut into them and these lids were placed on top of glass jar, cling film, agar and skin. Fresh tentacles were allowed to sting for $3 \mathrm{~min}$ before the test solutions were applied directly onto the tentacles using a spray bottle. Test solutions were: (a) control (no solution), (b) sea water, (c) vinegar, (d) urine and (e) Sting No More ${ }^{\circledR}$ Spray. Isopropanol was not used as there were only 15 agarose rounds due a shortage of ovine intestines during the experiment, and based on previous research the authors wanted to test the effectiveness of Sting No More Spray as a potential rinse solution. The tentacles remained for another $2 \mathrm{~min}$ before the skins and tentacles were removed. Photos were taken after $40 \mathrm{~min}$ and $12 \mathrm{~h}$ of incubation at room temperature.

To evaluate temperature treatments, 9 blood agar plates were acclimated to room temperature. Two tentacles were added to each blood agar plate and allowed to sting for three minutes before they were pulled off using tweezers. 3 plates each received (a) no temperature treatment (control); (b) an ice pack for $40 \mathrm{~min}$; and (c) a $45^{\circ} \mathrm{C}$ hot pack for $40 \mathrm{~min}$ (thus a total of $\mathrm{N}=6$ stings for each condition). Plates were incubated at room temperature. In the first experiment, photos were taken at $40 \mathrm{~min}$ and $24 \mathrm{~h}$. The experiment was then repeated; however, for the second experiment, photos were taken at $40 \mathrm{~min}, 3 \mathrm{~h}$ and $14 \mathrm{~h}$.

\subsection{Statistical Analyses}

For blood agar experiments, the area of the zone of hemolysis was calculated using ImageJ (the United States National Institutes of Health, Bethesda, MD, USA). Briefly, the image scale was set using the known widths and subsections $(50 \mathrm{~mm} \times 15 \mathrm{~mm}$ or $15 \mathrm{~mm} \times 7.5 \mathrm{~mm}$ ) were taken from each replicate for analysis to remove edge effects. Controls were used to set the color threshold for no hemolysis. The total area of the hemolytic zone was taken directly from the "analyze particles" function. Hemolytic zone was evaluated as the area exhibiting $>80 \%$ hemolysis. Shapiro-Wilk normality tests were conducted on the single timepoint data sets; since data were normally distributed, one-way ANOVAs were used. Two-way ANOVAs were used for multiple timepoint data sets. All statistical analyses and post-hoc multiple comparisons were conducted in GraphPad Prism version 6.0 (GraphPad Software, Inc., La Jolla, CA, USA).

Supplementary Materials: Zenodo DOI:10.5281/zenodo.832574 (https:/ / zenodo.org/record/832574) Video S1: Vinegar Application to Gelatin-Adherent Cnidae.

Acknowledgments: The authors thank Maeve Edwards, Margaret Flaherty and Ana Mendes for their hard work on these experiments. The authors also thank Aidan O'Donoghue for the collection of jellyfish sting data from Dublin; Chad Widmer and the Point Defiance Zoo and Aquarium for providing jellyfish specimens and bench space for experimental use for cnidae discharge experiments. This work was supported by a Fulbright Specialist Project (\#6977) to Doyle representing the host institution, National University of Ireland Galway, and Yanagihara, the visiting Fulbright Specialist, as well as by contracts from the U.S. Department of Defense, Special Operations Command to Yanagihara (USSOCOM H92222-14-P-0058, USSOCOM H92222-15-P-0067 007960-00002, H92222-14-P-0058 006719-00002), grants from the United States National Institutes of Health to Yanagihara (U54NS039406, P30GM114737, U54MD008419, G12RR003061, P20RR016453, R21DA024444), grants from the Victoria S. and Bradley L. Geist Foundation of the Hawaii Community Foundation to Yanagihara (HCF958935, HCF991879, 20001741, 20011908, 20061497, 20071368 and 47031) and a grant to Doyle from the European Union's Horizon 2020 research and innovation programme under grant agreement No: 678193EU (CERES Project).

Author Contributions: The studies were funded by grants obtained by A.A.Y. and T.K.D.; T.K.D. and A.A.Y. conceived and designed the experiments, which were performed in the laboratory of T.K.D. by T.K.D., J.L.H. and A.A.Y. and cnidae discharge experiments which were conducted on-site at the Point Defiance Zoo and Aquarium in Tacoma, WA, USA, by C.L.W.; E.M., A.A.Y., J.L.H. and T.K.D. performed jellyfish husbandry and collections in Ireland; C.L.W. and J.L.H. analyzed the data; and C.L.W., T.K.D. and A.A.Y. wrote and edited the manuscript with contributions from J.L.H. and E.M. 
Conflicts of Interest: A.A.Y. declares a potential conflict of interest as the inventor for the United States Patent and Trademark Office applications PCT/US2012/000095 and PCT/US2015/037974. A.A.Y. is also the founder and principal of Alatalab Solutions, Limited Liability Corporation manufacturer of Sting No More products. Management of this disclosed potential conflict of interest was achieved under an approved University of Hawaii Conflict of Interest (COI) plan. All aspects of the COI plan were followed while conducting this research study and in the independent analysis of data. C.L.W., J.L.H., E.M. and T.K.D. declare no conflicts of interest. The funding sponsors had no role in the design of the study; in the collection, analyses, or interpretation of data; in the writing of the manuscript, and in the decision to publish the results.

\author{
Abbreviations \\ MDPI Multidisciplinary Digital Publishing Institute \\ TSA \\ CEBM Centre for Evidence-Based Medicine \\ TBAA Tentacle Blood Agarose Assay \\ TSBAA Tentacle Skin Blood Agarose Assay
}

\title{
References
}

1. Barz, K.; Hirche, H.-J. Abundance, distribution and prey composition of scyphomedusae in the southern North Sea. Mar. Biol. 2007, 151, 1021-1033. [CrossRef]

2. Dawson, M.N. Cyanea capillata is not a cosmopolitan jellyfish: Morphological and molecular evidence for C. annaskala and C. rosea (Scyphozoa: Semaeostomeae: Cyaneidae) in south-eastern Australia. Invertebr. Syst. 2005, 19, 361-370. [CrossRef]

3. Dong, Z.; Liu, D.; Keesing, J.K. Jellyfish blooms in China: Dominant species, causes and consequences. Mar. Pollut. Bull. 2010, 60, 954-963. [CrossRef] [PubMed]

4. Doyle, T.K.; Houghton, J.D.R.; Buckley, S.M.; Hays, G.C.; Davenport, J. The broad-scale distribution of five jellyfish species across a temperate coastal environment. Hydrobiologia 2007, 579, 29-39. [CrossRef]

5. Kolbasova, G.D.; Zalevsky, A.O.; Gafurov, A.R.; Gusev, P.O.; Ezhova, M.A.; Zheludkevich, A.A.; Konovalova, O.P.; Kosobokova, K.N.; Kotlov, N.U.; Lanina, N.O.; et al. A new species of Cyanea jellyfish sympatric to C. capillata in the White Sea. Pol. Biol. 2015, 38, 1439-1451. [CrossRef]

6. Lord, R.E.; Wilks, S.L.B. A case of jellyfish sting simulating an acute abdomen. Lancet 1918, $192,390$. [CrossRef]

7. Russell, F.S. Vol II: Pelagic Scyphozoa with a supplement to the first volume on hydromedusae. In The Medusae of the British Isles; Cambridge University Press: Cambridge, UK, 1970.

8. Bastian, T.; Haberlin, D.; Purcell, J.E.; Hays, G.C.; Davenport, J.; McAllen, R.; Doyle, T.K. Large-scale sampling reveals the spatio-temporal distributions of the jellyfish Aurelia aurita and Cyanea capillata in the Irish Sea. Mar. Biol. 2011, 158, 2639-2652. [CrossRef]

9. Burnett, J.W. Medical aspects of jellyfish envenomation: Pathogenesis, case reporting and therapy. Hydrobiologia 2001, 451, 1-9. [CrossRef]

10. Burnett, J.W.; Calton, G.J. Venomous pelagic coelenterates-Chemistry, toxicology, immunology and treatment of their stings. Toxicon 1987, 25, 581-602. [CrossRef]

11. Suput, D. In vivo effects of cnidarian toxins and venoms. Toxicon 2009, 54, 1190-1200. [CrossRef] [PubMed]

12. Tibballs, J. Australian venomous jellyfish, envenomation syndromes, toxins and therapy. Toxicon 2006, 48, 830-859. [CrossRef] [PubMed]

13. Tønseth, A. Health damage after jellyfish stings. J. Nor. Med. Assoc. 2007, 127, 1777-1778. (In Norwegian)

14. Williamson, J.A.; Fenner, P.J.; Burnett, J.W.; Rifkin, J.F. Venomous \& Poisonous Marine Animals: A Medical and Biological Handbook; Surf Life Saving Australia and University of New South Wales Press: Sydney, Australia, 1996.

15. Little, M.; Pereira, P.; Carrette, T.; Seymour, J. Jellyfish responsible for irukandji syndrome. QJM Int. J. Med. 2006, 99, 425-427. [CrossRef] [PubMed]

16. Hoffmann, F.R.; Jungblut, S.; Holst, S.; Kappertz, G.; Berlitz, P.; Ohmann, T. Therapieoptionen bei vernesselungen durch quallen an deutschen küstengewässern. Notf. Rett. 2016, 1-7. (In German) [CrossRef] 
17. Centre for Evidence-Based Medicine. Oxford Centre for Evidence-Based Medicine-Levels of Evidence. Available online: http:/ / www.cebm.net/oxford-centre-evidence-based-medicine-levels-evidence-march2009/ (accessed on 8 February 2017).

18. Cegolon, L.; Heymann, W.C.; Lange, J.H.; Mastrangelo, G. Jellyfish stings and their management: A review. Mar. Drugs 2013, 11, 523-550. [CrossRef] [PubMed]

19. Ward, N.T.; Darracq, M.A.; Tomaszewski, C.; Clark, R.F. Evidence-based treatment of jellyfish stings in North America and Hawaii. Ann. Emerg. Med. 2012, 60, 399-414. [CrossRef] [PubMed]

20. Exton, D.R.; Fenner, P.J.; Williamson, J.A. Cold packs-Effective topical analgesia in the treatment of painful stings by Physalia and other jellyfish. Med. J. Aust. 1989, 151, 625-626. [PubMed]

21. Fenner, P.J.; Fitzpatrick, P.F. Experiments with the nematocysts of Cyanea capillata. Med. J. Aust. 1986, 145, 174. [PubMed]

22. Yanagihara, A.A.; Wilcox, C.L. Cubozoan sting-site seawater rinse, scraping, and ice can increase venom load: Upending current first aid recommendations. Toxins 2017, 9, 105. [CrossRef] [PubMed]

23. DeClerck, M.P.; Bailey, Y.; Craig, D.; Lin, M.; Auerbach, L.J.; Linney, O.; Morrison, D.E.; Patry, W.; Auerbach, P.S. Efficacy of topical treatments for Chrysaora chinensis species: A human model in comparison with an in vitro model. Wilderness Environ. Med. 2016, 27, 25-38. [CrossRef] [PubMed]

24. Berling, I.; Isbister, G. Marine envenomations reply. Aust. Fam. Physician 2015, 44, 168.

25. Burnett, J.W. Treatment of Atlantic cnidarian envenomations. Toxicon 2009, 54, 1201-1205. [CrossRef] [PubMed]

26. TOXBASE Entry for Jelly Fish Sting (UK Waters). Available online: http://toxbase.org (accessed on 28 July 2016).

27. Auerbach, P.S. Envenomations from jellyfish and related species. J. Emerg. Nurs. 1997, 23, 555-565. [CrossRef]

28. Honeycutt, J.D.; Jonas, C.E.; Smith, R.F. FPIN's Clinical Inquiries: Treatment of jellyfish envenomation. Am. Fam. Physician 2014, 89, 823A-823C. Available online: http://www.aafp.org/afp/2014/0515/od1.pdf (accessed on 8 February 2017).

29. Auerbach, P.S. Marine envenomations. N. Engl. J. Med. 1991, 325, 486-493. [PubMed]

30. Markenson, D.; Ferguson, J.D.; Chameides, L.; Cassan, P.; Chung, K.-L.; Epstein, J.; Gonzales, L.; Herrington, R.A.; Pellegrino, J.L.; Ratcliff, N.; et al. Part 17: First Aid. Circulation 2010, 122, S934-S946. [CrossRef] [PubMed]

31. Weinstein, S.A.; Dart, R.C.; Staples, A.; White, J. Envenomations: An overview of clinical toxinology for the primary care physician. Am. Fam. Physician 2009, 80, 793-802. [PubMed]

32. McGoldrick, J.; Marx, J.A. Marine envenomations Part 2: Invertebrates. J. Emerg. Med. 1992, 10, 71-77. [CrossRef]

33. Australian Resuscitation Council. Guideline 9.4.5: Envenomation-Jellyfish Stings. Available online: https:/ / resus.org.au/?wpfb_dl=41 (accessed on 8 February 2017).

34. Gershwin, L.-A. The Jellyfish App: Sting Treatment. Available online: http://thejellyfishapp.com/treatment (accessed on 8 February 2017).

35. Fenner, P.J. Marine envenomation: An update-A presentation on the current status of marine envenomation first aid and medical treatments. Emerg. Med. Aust. 2000, 12, 295-302. [CrossRef]

36. Yanagihara, A.A.; Wilcox, C.; King, R.; Hurwitz, K.; Castelfranco, A.M. Experimental assays to assess the efficacy of vinegar and other topical first-aid approaches on cubozoan (Alatina alata) tentacle firing and venom toxicity. Toxins 2016, 8, 19. [CrossRef] [PubMed]

37. Östman, C.; Hydman, J. Nematocyst analysis of Cyanea capillata and Cyanea lamarckii (Scyphozoa, Cnidaria). Sci. Mar. 1997, 61, 313-344.

38. Burnett, J.W.; Ordonez, J.V.; Calton, G.J. Differential toxicity of Physalia physalis (Portuguese man o' war) nematocysts separated by flow cytometry. Toxicon 1986, 24, 514-518. [CrossRef]

39. Endean, R.; Rifkin, J. Isolation of different types of nematocyst from cubomedusan Chironex fleckeri. Toxicon 1975, 13, 375-376. [CrossRef]

40. Helmholz, H.; Wiebring, A.; Lassen, S.; Ruhnau, C.; Schuett, C.; Prange, A. Cnidom analysis combined with an in vitro evaluation of the lytic, cyto- and neurotoxic potential of Cyanea capillata (Cnidaria: Scyphozoa). Sci. Mar. 2012, 76, 339-348. [CrossRef]

41. Auerbach, P.S. In reply to evidence-based treatment of jellyfish stings in North America and Hawaii. Ann. Emerg. Med. 2013, 61, 253-254. [CrossRef] [PubMed] 
42. Wilcox, C.L.; Headlam, J.L.; Doyle, T.K.; Yanagihara, A.A. Assessing the efficacy of first-aid measures in Physalia sp. envenomation, using solution- and blood agarose-based models. Toxins 2017, 9, 149. [CrossRef] [PubMed]

43. Wilcox, C.L.; Yanagihara, A.A. Heated debates: Hot-water immersion or ice packs as first aid for cnidarian envenomations? Toxins 2016, 8, 97. [CrossRef] [PubMed]

44. Loten, C.; Stokes, B.; Worsley, D.; Seymour, J.E.; Jiang, S.; Isbister, G.K. Randomised controlled trial of hot water $\left(45^{\circ} \mathrm{C}\right)$ immersion versus ice packs for pain relief in bluebottle stings. Med. J. Aust. 2006, 184, 329-333. [PubMed]

45. Nomura, J.T.; Sato, R.L.; Ahern, R.M.; Snow, J.L.; Kuwaye, T.T.; Yamamoto, L.G. A randomized paired comparison trial of cutaneous treatments for acute jellyfish (Carybdea alata) stings. Am. J. Emerg. Med. 2002, 20, 624-626. [CrossRef] [PubMed]

46. Thomas, C.S.; Scott, S.A.; Galanis, D.J.; Goto, R.S. Box jellyfish (Carybdea alata) in Waikiki: Their influx cycle plus the analgesic effect of hot and cold packs on their stings to swimmers at the beach: A randomized, placebo-controlled, clinical trial. Hawaii Med. J. 2001, 60, 100-107. [PubMed]

47. Muirhead, D. Applying pain theory in fish spine envenomation. J. S. Pac. Underw. Med. Soc. 2002, 32, 150-153.

48. Marino, A.; Crupi, R.; Rizzo, G.; Morabito, R.; Musci, G.; La Spada, G. The unusual toxicity and stability properties of crude venom from isolated nematocysts of Pelagia noctiluca (Cnidaria, Scyphozoa). Cell. Mol. Biol. 2007, 53, 994-1002.

49. Morabito, R.; Costa, R.; Rizzo, V.; Remigante, A.; Nofziger, C.; La Spada, G.; Marino, A.; Paulmichl, M.; Dossena, S. Crude venom from nematocysts of Pelagia noctiluca (Cnidaria: Scyphozoa) elicits a sodium conductance in the plasma membrane of mammalian cells. Sci. Rep. 2017, 7, 41065. [CrossRef] [PubMed]

50. Baxter, E.H.; Marr, A.G.M. Sea wasp (Chironex fleckeri) venom: Lethal, haemolytic and dermonecrotic properties. Toxicon 1969, 7, 195-210. [CrossRef]

51. Carrette, T.J.; Cullen, P.; Little, M.; Peiera, P.L.; Seymour, J.E. Temperature effects on box jellyfish venom: A possible treatment for envenomed patients? Med. J. Aust. 2002, 177, 654-655. [PubMed]

52. Chung, J.J.; Ratnapala, L.A.; Cooke, I.M.; Yanagihara, A.A. Partial purification and characterization of a hemolysin (CAH1) from Hawaiian box jellyfish (Carybdea alata) venom. Toxicon 2001, 39, 981-990. [CrossRef]

53. Endean, R.; Henderson, L. Further studies of toxic material from nematocysts of cubomedusan Chironex fleckeri Southcott. Toxicon 1969, 7, 303-314. [CrossRef]

54. Koyama, T.; Noguchi, K.; Matsuzaki, T.; Sakanashi, M.; Nakasone, J.; Miyagi, K.; Sakanashi, M.; Sakanashi, M. Haemodynamic effects of the crude venom from nematocysts of the box-jellyfish Chiropsalmus quadrigatus (Habu-kurage) in anaesthetized rabbits. Toxicon 2003, 41, 621-631. [CrossRef]

55. Monastyrnaya, M.M.; Zykova, T.A.; Apalikova, O.V.; Shwets, T.V.; Kozlovskaya, E.P. Biologically active polypeptides from the tropical sea anemone Radianthus macrodactylus. Toxicon 2002, 40, 1197-1217. [CrossRef]

56. Cuiping, L.; Pengcheng, L.; Jinhua, F.; Rongfeng, L.; Huahua, Y. Cytotoxicity of the venom from the nematocysts of jellyfish Cyanea nozakii Kishinouye. Toxicol. Ind. Health 2012, 28, 186-192. [CrossRef] [PubMed]

57. Feng, J.; Yu, H.; Li, C.; Xing, R.; Liu, S.; Wang, L.; Cai, S.; Li, P. Isolation and characterization of lethal proteins in nematocyst venom of the jellyfish Cyanea nozakii Kishinouye. Toxicon 2010, 55, 118-125. [CrossRef] [PubMed]

58. Garcia-Arredondo, A.; Murillo-Esquivel, L.J.; Rojas, A.; Sanchez-Rodriguez, J. Characteristics of hemolytic activity induced by the aqueous extract of the Mexican fire coral Millepora complanata. J. Venom Anim. Toxins Incl. Trop. Dis. 2014, 20, 49. [CrossRef] [PubMed]

59. Hernandez-Matehuala, R.; Rojas-Molina, A.; Vuelvas-Solorzano, A.A.; Garcia-Arredondo, A.; Ibarra Alvarado, C.; Olguin-Lopez, N.; Aguilar, M. Cytolytic and systemic toxic effects induced by the aqueous extract of the fire coral Millepora alcicornis collected in the Mexican Caribbean and detection of two types of cytolisins. J. Venom Anim. Toxins Incl. Trop. Dis. 2015, 21, 36. [CrossRef] [PubMed]

60. Kang, C.; Munawir, A.; Cha, M.; Sohn, E.-T.; Lee, H.; Kim, J.-S.; Yoon, W.D.; Lim, D.; Kim, E. Cytotoxicity and hemolytic activity of jellyfish Nemopilema nomurai (Scyphozoa: Rhizostomeae) venom. Comp. Biochem. Physiol. C 2009, 150, 85-90. [CrossRef] [PubMed] 
61. Li, R.; Yu, H.; Xing, R.; Liu, S.; Qing, Y.; Li, K.; Li, B.; Meng, X.; Cui, J.; Li, P. Isolation and in vitro partial characterization of hemolytic proteins from the nematocyst venom of the jellyfish Stomolophus meleagris. Toxicol. In Vitro 2013, 27, 1620-1625. [CrossRef] [PubMed]

62. Marino, A.; Valveri, N.; Muia, C.; Crupi, R.; Rizzo, G.; Musci, G.; La Spada, G. Cytotoxicity of the nematocyst venom from the sea anemone Aiptasia mutabilis. Comp. Biochem. Physiol. C 2004, 139, 295-301. [CrossRef] [PubMed]

63. Noguchi, K.; Sakanashi, M.; Matsuzaki, T.; Nakasone, J.; Sakanashi, M.; Koyama, T.; Hamadate, N.; Sakanashi, M. Cardiovascular effects and lethality of venom from nematocysts of the box-jellyfish Chiropsalmus quadrigatus (Habu-kurage) in anaesthetized rats. Toxicon 2005, 45, 519-526. [CrossRef] [PubMed]

64. Pereira, P.; Seymour, J.E. In vitro effects on human heart and skeletal cells of the venom from two cubozoans, Chironex fleckeri and Carukia barnesi. Toxicon 2013, 76, 310-315. [CrossRef] [PubMed]

65. Fenner, P.J. The Global Problem of Cnidarian (Jellyfish) Stings. M.D. Thesis, University of London, London, UK, 1997.

(C) 2017 by the authors. Licensee MDPI, Basel, Switzerland. This article is an open access article distributed under the terms and conditions of the Creative Commons Attribution (CC BY) license (http:/ / creativecommons.org/licenses/by/4.0/). 